CRÍTICA, Revista Hispanoamericana de Filosofia

Vol. XXV, No. 74 (agosto 1993): 65-104

\title{
IDEALISMO TRASCENDENTAL Y REALISMO EMPÍRICO
}

\author{
Manuel García Serrano
}

\section{I}

En una conocida carta a Herz, sugería Kant que el problema de saber "en qué fundamento se apoya la relación con el objeto de lo que se llama representación dentro de nosotros" constituye "la clave de todo el misterio de la hasta ahora enfoscada metafísica". ${ }^{1}$ En la obra kantiana capital este enigma se enlaza paradigmáticamente con las embarazosas cuestiones epistemológicas envueltas en la relación entre el "mundo sensible", concebido como un receptivo producto causal, en nuestra conciencia, de los objetos exteriores y de los avatares de nuestro propio cuerpo, y el "mundo inteligible", concebido como un producto conceptual espontáneo o abductivo. Tradicionalmente, la disparidad entre uno y otro mundos ha recibido distintos acentos. En cierto modo, por ejemplo, se diría que en el primero de los mundos en cuestión hemos de considerar a cada sujeto, y a nosotros mismos, como un objeto más en el Universo, mientras que en el segundo de esos mundos cada sujeto, según la metáfora pascaliana, absorbe al Universo entero en $s u$ pensamiento. ${ }^{2}$

1 Akademie $X$, carta no. 67, p. 130.

2 Blaise Pascal, Pensées, en Euvres Complètes, Gallimard, 1954, p. 1157. 
Si damos en acentuar ahí un sentido de parcialidad individual, nos la veremos enseguida con una tercera dicotomía: la de subjetividad/objetividad, y la confrontación primaria entre esquemas conceptuales y objetos pasará entonces a asumir un papel secundario, toda vez que los esquemas conceptuales, en tanto esquemas de un sujeto, podrán ser sometidos a sucesivas consideraciones "objetivas". Así ocurrirá siempre que avancemos un paso más allá del nivel en que se sitúe nuestro conceptualizado punto de vista momentáneo acerca de cierto aspecto del mundo y contemplemos ese punto de vista temporal, y su correspondiente parcela mundana, como objetos ambos que abarcamos en una nueva cosmovisión. ${ }^{3}$ Cuanto más nos desprendamos, a través de pasos abarcadores sucesivos de esta índole, de rasgos personales prendidos en nuestras estratificables visiones del mundo, tanto más objetiva será la visión a la que arribemos. De esta guisa, por ejemplo, advertimos primero un desengaño del corazón; luego paramos mientes tal vez en el peculiar tenor del afecto amoroso, o en los criterios que han guiado nuestra apreciación de lo que en tal caso hace desengañadoras a unas circunstancias; después quizá percibimos que el rudimento de teoría del amor en que hemos recalado es afín -o precisamente no lo es- al modelo de cierta educación sentimental, amigo, o enemigo, de una tradición... Sobra decir que en este proceso la singularidad subjetiva de cada uno de nosotros, seres limitados y finitos, no será nunca rebasada por completo, toda vez que en cada etapa del proceso hay al menos un estado del sujeto pensante que no es objetivado.

Mas, en cualquier caso, cuando Kant habla de las condiciones subjetivas del conocimiento no tiene a la vista esta

${ }^{3}$ Este curso de la dualidad subjetividad/objetividad es el que, por ejemplo, encontramos en la obra de Thomas Nagel, The View from Nowhere, Oxford University Press, Nueva York, 1986. 
acepción de la noción de subjetividad. Lo subjetivo no es para él sinónimo de parcial, peculiar o personal, sino que pretende designar un ámbito regulado de la capacidad cognoscitiva de la especie humana en el que se hallarían sedimentadas condiciones de toda experiencia posible. ${ }^{4}$ Siendo el reconocimiento de algo como algo una función que depende tanto del objeto conocido cuanto de estas condiciones preempíricas, el uso predominante de las nociones de conocimiento real o de verdad, y su contraposición a la fantasía o al error, se ve forzado a presuponer no sólo que los sujetos cognoscitivos comparten un mundo común, que se pretende conocer, sino que comparten también estructuras cognoscitivas que condicionan análogamente sus experiencias. En otro caso, sus ocasionales imputaciones mutuas de falsedad o desatino, así como sus respectivas conformidades, tendrían un sentido más que dudoso, porque no dispondrían de una posible medida común. Kant, como buen ilustrado, identificó esas estructuras cognoscitivas con la idea de Razón y, para no obturar el cauce de la innegable perseverancia del error, atribuyó a la Razón misma ciertas inevitables tendencias especulativas desbaratadas. Con ello, la Razón sería la fuente, por ejemplo, de las ensoñaciones de la metafísica dogmática, al tiempo que nos otorgaría recursos que son imprescindibles para, conjuntamente, detectar sus propias predisposiciones achacosas y sus enredos y para alcanzar una visión concertada de la realidad de las

4 En la obra de Kant, el carácter no objetual del sujeto adquiere así un sello singular. La disparidad entre el yo que es percibido o pensado como objeto individual entre otros objetos individuales y el yo pensante, que abarca el conjunto de esos objetos y sus actividades, es el tema de los Paralogismos en la primera Crítica (KrV A342-405, B400-432), donde la función básica del yo pensante - conectada estrechamente con la justificación del denominado idealismo trascendental, como enseguida habremos de ver- no es al cabo susceptible de una objetivación estricta, en cuanto que habría de ser un fundamento no clausurable de toda cosmovisión. 
cosas. En esta representación general está contenida, a su vez, la clave de la característica intelección kantiana acerca de la conexión entre el mundo receptivo de los sentidos y el peculiar mundo de los conceptos. La Razón proporciona un armazón intelectual intersubjetivo de categorías básicas, no libre de defectos, al que se habría de acomodar toda experiencia sensible de las cosas. Ese armazón sería la base común para todas las sucesivas construcciones teóricas. Pero serían precisamente los tozudos estados de cosas reales los que nos proveerían de las experiencias que esas teorías ordenan. La Razón articula nuestras experiencias, pero no las crea. Con el fin de hacer justicia a los dos polos de esta sencilla intelección, Kant se declaró a la vez idealista trascendental y realista empírico. Dedicaremos las siguientes páginas a examinar estas nociones.

\section{II}

Realismo e idealismo son doctrinas ontológicas que pueden adoptar distintas formas. En lo que atañe al realismo empírico, Leslie Stevenson ha propuesto un interesante criterio de definición demarcativa con el recurso de la noción auxiliar de "proposición independiente". ${ }^{5}$ Una proposición $p$ es independiente del juicio de un sujeto dado $a$ si, $\mathrm{y}$ sólo si, $p$ ni es incorregible, ni es autoevidente para $a$. Si del juicio de buena $f e$ de $a$ de que $p$ se sigue que $p$ es verdad, $p$ será incorregible para $a$. Cuando a su vez, siendo $p$ una proposición verdadera, de la sola consideración de si $p$ por parte de $a$ se siga que $a$ juzgará que $p, p$ será autoevidente para $a$. Proposiciones característicamente no independientes son las invocadas por Descartes como seguras evidencias primarias del yo pensante; que en este preciso momento tengo dolor de cabeza, me siento angustiado,

5 Cfr. L. Stevenson, The Metaphysics of Experience, Clarendon Press, Oxford, 1982. 
percibo algo, estoy meditando un problema o imaginando que soy rico, son todas ellas, una vez provistas de índices temporales y personales, proposiciones no independientes: ocasionalmente son autoevidentes e incorregibles. Dada la peculiaridad de estas proposiciones, su emisión en primera persona difícilmente puede ser computada como un normal acto de habla asertivo, si asociamos a éste, como de ordinario se hace, una pretensión de verdad. En la emisión de proposiciones que no son independientes esa pretensión resulta difuminada, por cuanto la verdad se cumple con la sola satisfacción de una condición comunicativa de sinceridad y, tras la realización no defectiva del acto de habla, no se requieren justificaciones veritativas adicionales. Si el emisor no miente, la proposición corresponderá al estado de las cosas. La sola justificación que el emisor puede ofrecer a un interlocutor incrédulo es alguna prueba práctica de su propia veracidad. Si es cierto que él es veraz, lo que dice también será cierto. Esto no es en cambio lo que ocurre con las aseveraciones usuales: en tales casos la sinceridad de una creencia no garantiza su buen tino y, al contrario, queriendo mentir, alguien puede decir algo que es verdad. De ahí que en tal contexto las justificaciones veritativas tomen otro cariz y que al acto de habla asertivo lo secunde peculiarmente una pretensión de verdad. Si no cabe asentir racionalmente a dicha pretensión, el acto de habla asertivo no tendrá con todo ninguna mácula ilocucionaria. Mas si en la emisión de una proposición no independiente los hechos no se corresponden con la proposición, ciertas condiciones que son base de la comunicación se habrán contravenido.

Estas observaciones parecen confirmar, entonces, que todo acto asertivo genuino - frente a los actos de habla que bien está llamar expresivos- está relacionado con proposiciones independientes y que, en virtud precisamente del carácter siempre problemático o falibilista de las enuncia- 
ciones de éstas, el hablante no puede arrogarse al respecto más que una pretensión de verdad, intersubjetivamente disputable, mas no una absoluta certeza. En el catálogo de doctrinas ontológicas hay lugar, sin embargo, para otras concepciones multicolores que omiten la distinción que acabamos de formular, o no le dan valor. Siguiendo el criterio de Stevenson, como solipsista cabe definir a aquel imaginable filósofo que afirme que hay al menos una persona para la que ninguna proposición es independiente de su juicio. Idealista subjetivo es aquel otro que sostiene que para todo sujeto hay alguna proposición que es independiente de $s u$ juicio, pero no del juicio de todos los demás. Como realista empírico designaremos, por último, a todo el que crea que existe alguna proposición independiente del juicio de todo el mundo. Según el solipsista, hay alguien que nunca puede estar en el error. Según el idealista subjetivo, cada uno puede estar en el error en algo, pero no todo el mundo puede estar simultáneamente en el error acerca de la misma cosa. En cambio, según el realista empírico, puede haber algo en lo que todo el mundo que lo somete actualmente a su consideración y juicio se equivoca a la vez. ${ }^{6}$

Los estados internos de conciencia que forman el contenido de las proposiciones no independientes prototípicas arriba mencionadas son estados actuales; ni futuros, ni pasados. Que ayer tuve momentos de entusiasmo, o que los tendré mañana no parecen proposiciones incorregibles y autoevidentes. La cuantificación de la variable tiempo, empero, abre espacio en principio a dos versiones extremadas de idealismo subjetivo y de solipsismo. ${ }^{7}$ Esas versiones niegan, en oposición a sus imaginables contraversiones moderadas o laxas, que en todo momento exista alguna proposición independiente del juicio de cada uno. Para el

${ }^{6}$ Cfr. L. Stevenson, op. cit., pp. 35-36.

${ }^{7}$ Id., pp. 36-38. 
solipsista e idealista subjetivo moderados, en cambio, toda aquella proposición que se refiera a un tiempo distinto al momento temporal de su enunciación sería una proposición independiente. Entre tales proposiciones habría que contar, entonces, también a las que informan de los propios estados de conciencia no actuales. Las versiones moderadas de idealismo subjetivo y de solipsismo afirman su orientación antirrealista, por lo tanto, sólo con respecto a proposiciones en tiempo presente (o más exactamente: con respecto a proposiciones con el mismo índice temporal que su enunciación). En una significada sub-versión de esta versión de idealismo subjetivo, las proposiciones no independientes más relevantes serían proposiciones observacionales de primera persona en presente; el resto del lenguaje no observacional de cada sujeto, así como sus creencias asociadas, habría de ser reconstruido a partir de esta base. Todo sujeto podría, individualmente, formarse falsas creencias ligadas a proposiciones referidas a las observaciones de otros y a sus propias observaciones pasadas, pero las creencias ligadas a sus propias observaciones actuales nunca serían falsas. ${ }^{8}$ Complementariamente, el básico núcleo idealista de esta concepción descartaría la posibilidad de que haya proposiciones en tiempo presente que no sean contenido posible $-\mathrm{o}$ también de él derivado o inducido, o a él reducible - de un enunciado observacional actual de alguien: una tal proposición, terminantemente independiente del juicio de todo el mundo a la vez, habría de ser un sinsentido.

Las versiones radicales de idealismo subjetivo y de solipsismo, por su parte, desestiman una consideración sustancial del pasado, porque no distinguen lógicamente con nitidez la proposición que informa hoy del propio dolor de

8 Cada certeza sería entonces fugaz, pero estaríamos siempre en alguna certeza, y muchas viejas certezas serían revivibles. 
muelas de hoy de la que lo hace, respecto al mismo suceso, mañana. Incluso a filósofos profesionales han de resultarles estas últimas ontologías radicalizadas demasiado excéntricas. Quien las profese no podrá hacer comprensible la familiar tarea de corrección de nuestras sucesivas creencias propias. ¿Qué razón de ser habría para admitir una diferencia entre la corrección consciente de una opinión propia cualquiera - que tiene necesariamente un índice temporal anterior al índice de la corrección - y la creencia actual desatenta, o pseudocreencia, en dos proposiciones incompatibles? Sin una consideración más distintiva del pasado es difícil imaginarse, igualmente, que se pueda rendir cuenta de nuestra experiencia de unidad de conciencia, que parece basada, justamente, en el reconocimiento de que representaciones distanciadas en el tiempo se asocian a un mismo yo. ${ }^{9}$ ¿Cómo llegaríamos a conformar una autoconciencia si estuviera excluida la posibilidad de realizar juicios peculiarmente diferenciados sobre los propios estados de conciencia pretéritos? ${ }^{10}$ Lo que tiene monta es que éstas no son solamente alegaciones contra esas extravagantes versiones de solipsismo e idealismo, sino decisivas alegaciones generales a favor de una posición realista.

No es tampoco probable que encontremos en nuestra postwittgensteiniana era filosófica muchos solipsistas moderados, pero sí, en cambio, respetados idealistas subjetivos moderados. Adviértase, en todo caso, que un realista

9 Peter Strawson resume el alcance de esta experiencia en los siguientes términos: "la historia de un hombre es - entre otras muchas cosas - el hacerse cuerpo de un punto de vista extendido temporalmente en el mundo" (Los limites del sentido, Madrid, 1975, p. 93). Lo peculiar de esta experiencia es que está enhebrada en cada otra experiencia.

10 Cfr. las consideraciones al respecto de Jonathan Bennett en La "Crítica de la razón pura" de Kant. La Analitica, Madrid, 1979, pp. 143-144, 246 ss. 
empírico tolerante puede aceptar de buen grado una formulación más atenuada de la intuición central de la afamada sub-versión idealista a la que antes aludimos: es fácil imaginar proposiciones observacionales de tiempo presente independientes del juicio actual de todo sujeto, pero tal vez la figuración de proposiciones tales independientes del juicio posible de todo sujeto sea, en efecto, un despropósito. Me aventuro a afirmar que la proposición "sobre la cama de Serrano yace una serpiente" es independiente del juicio actual de todo sujeto, toda vez que nadie está ahora en mi dormitorio. Sin duda hay algún sujeto - por ejemplo, un ciego o todo aquél que no sepa nada de serpientes - para el que esa proposición sería independiente aun cuando se encontrase en mi dormitorio. Pero encuentro contraintuitivo atribuir independencia a esa proposición con respecto al juicio de todo sujeto que, contrafácticamente, se encontrara en mi dormitorio en este momento. Ahora bien, en primer lugar nuestro buen realista no se sentirá inclinado a pensar que las proposiciones observacionales sean base sólida suficiente para reducir el resto de las proposiciones de un lenguaje. En relación con estas proposiciones no observacionales, especialmente equipadas de carga teórica, el realista empírico seguirá siendo un ortodoxo realista; y, por ende, también lo seguirá siendo respecto a las proposiciones del lenguaje en su conjunto. En segundo lugar, el punto clave de la posición realista atañe hasta aquí solamente a la independencia de los estados de cosas respecto al juicio de cada sujeto en sus circunstancias actuales, mas no respecto al juicio posible de cada sujeto en circunstancias contrafácticas óptimas.

\section{III}

Si hay proposiciones independientes, ha de haber un mundo independiente. Esto es, si hay proposiciones que no 
son verdaderas sólo porque un sujeto, o una completa comunidad de sujetos, asienta a ellas, o asentiría a ellas si las sometiera a su consideración, entonces la verdad de esas proposiciones depende de algo más que las pertinentes creencias de esos sujetos. En lo que atañe al valor de verdad de esas proposiciones, todos los sujetos pueden tener representaciones falsas. Pero para que esta idea misma de representación falsa tenga fundamento, el realismo empírico requiere una clara dicotomía entre las experiencias de objetos y los objetos de esas experiencias. El realismo kantiano se halla precisamente en conexión con la distinción entre, por una parte, las relaciones temporales de las diferentes experiencias de un sujeto y, por otra, las relaciones temporales - basadas en la duradera unidad de la estructura espacial del mundo - de los objetos de esas experiencias. ${ }^{11}$ Kant sostiene que si bien nuestras representaciones empíricas varían constantemente y se reemplazan en sucesión, la estructura espacial del mundo tiene la identidad estable suficiente para garantizar tanto la posibilidad de reencontrar los mismos objetos de viejas experiencias, como la posibilidad de que ciertas experiencias de diversos sujetos sean experiencias de un mismo objeto. Cabe detectar tras esta tesis kantiana argumentos de distinto orden, basados en la consideración de ciertas singulares experiencias en esa sucesión de experiencias: a) Si negáramos la independencia de la realidad exterior, esto es, si por ejemplo imagináramos que los objetos de nuestras experiencias empíricas se diluyen tan pronto como nos enfrascamos en otras nuevas experiencias diferentes, no cabría dar sentido a la ya mencionada perspicua experiencia propia de identidad del yo, en cuanto que esta experiencia está basada en

11 Ésta es la probable enseñanza de la "Refutación del idealismo" en conjunción con la primera Analogía. Véase el agudo comentario de Strawson a este punto, op. cit., pp. 111-118. 
la sucesión temporal de experiencias en una ruta subjetiva sobre un mundo objetivo, bajo la suposición de que caben otras rutas de experiencia sobre el mismo mundo. De este modo, la idea de mundo asociada a nuestra historia personal entraña la independencia del mundo en su conjunto respecto a esa historia. ${ }^{12}$ b) Nuestras experiencias empíricas presuponen una realidad objetiva independiente en tanto que en esas experiencias desempeñan un papel decisivo la identificación de objetos ya experimentados y el reconocimiento de instancias de tipos familiares. Nótese que lo que de ordinario hacemos no es identificar o reconocer la experiencia de un objeto individual o instancia, toda vez que eso implicaría que lo habitual es tener la experiencia de una experiencia, cuando en realidad lo que por lo común tenemos es la experiencia de un objeto. No experimentamos la experiencia de tener la misma experiencia de antes. Experimentamos lo mismo que antes. No percibimos una experiencia de una mesa y comparamos esa experiencia con otra idéntica o análoga, sino que simplemente vemos (experimentamos) una mesa, que identificamos como la misma mesa de antes o reconocemos como instancia del tipo mesa, dando por sentado que esa mesa ha existido en el tiempo en el que se mantuvo fuera de nuestro campo visual y que hay - o al menos hubo - otras mesas que ahora no vemos. c) Nuestra aprehensión del mundo se produce en forma de experiencias sucesivas. Así pues, a través únicamente de la forma de esa aprehensión no podemos llegar a las experiencias peculiares de simultaneidad o permanencia, sino

12 Si abdicara de aquella suposición, no podría en rigor concebir el curso de mi identidad personal, toda vez que este curso gana su peculiaridad individual sólo en tanto me autositúo en el mundo y reconozco localizadamente otros cursos subjetivos sobre ese mismo mundo. En este sentido observa Kant que "la determinación de mi existencia en el tiempo es sólo posible merced a la existencia de las cosas que percibo fuera de mí", KrV B275. 
que hemos de suponer adicionalmente algo que tenga una realidad estable en algún grado tras nuestras experiencias momentáneas, por referencia a lo cual justamente diferenciamos la permanencia del cambio y la simultaneidad de la sucesión. ${ }^{13}$ Adicionalmente a las relaciones temporales de nuestras representaciones, sobreentendemos un sustrato estable de relaciones espaciales y temporales objetivas, y coordinamos nuestras representaciones y las representaciones intersubjetivas guiados por la idea regulativa de que ese sustrato existe.

IV

Las relaciones, en suma, que paulatinamente se tejen entre las experiencias de cada sujeto, conformando sistemas de creencias empíricas, no son necesariamente las mismas relaciones que entretejen a los objetos de nuestras experiencias. Esto abre cauce a la independencia de ciertas proposiciones. Kant, entonces, es ciertamente un realista empírico. Pero es también, al mismo tiempo, un idealista trascendental. En razón de su realismo empírico, Kant asienta una cierta sustancialidad de los objetos del mundo al margen de nuestros contingentes encuentros conscientes con ellos. Pero en razón de su idealismo trascendental, da una base conceptual a la propia sustancialidad de esos objetos en tanto objetos de experiencia posible. Esta forma singular de idealismo, que es el rasgo más caracterizado de su filosofía, está asociado en su primera gran Crítica al argumento capital de la llamada deducción trascendental. ${ }^{14}$ En lo que atañe al

$13 \mathrm{KrV}$ B225, 226.

$14 \mathrm{KrV}$ A84-130, B117-169. La asociación del idealismo trascendental con las llamadas formas puras de la sensibilidad - el espacio y el tiempo- nos interesa aquí menos.

La más frecuente actitud en la literatura analítica sobre Kant comprende una vindicación hermenéuticamente generosa de su realismo, 
rango deductivo de esta "deducción", Kant subraya cuidadosamente que no es estricto y que él habla de deducción del modo en que lo harían los juristas cuando aplican el término a sus pruebas y alegaciones en cuestiones de derecho informales. "Trascendental" es uno de los términos kantianos claves y, aunque Kant no lo usa con toda coherencia, y sí, más bien, con algún abuso, debe ser entendido como un predicado especial de otras nociones y claramente diferenciado de "trascendente", que califica las actividades y entidades especulativas que rebasan nuestras capacidades de escrutinio empírico. Un conocimiento es trascendental, dice Kant, cuando es conocimiento no de un objeto, sino de nuestro modo a priori de conocerlo. ${ }^{15}$ Claro es que con lo a priori nos vemos confrontados a otra noción problemática. Para nuestros fines, no obstante, basta retener que un conocimiento es trascendental siempre que tenga por contenido condiciones conceptuales irrebasables, o cuasi irrebasables, del conocimiento de los objetos de la experiencia posible. $\mathrm{O}$ dicho de otro modo: trascendental es aquel conocimiento que se ocupa de las condiciones de todo conocimiento en absoluto. Para comprender el objetivo de la "deducción trascendental" kantiana, hemos de mantenerla ligada a este

al tiempo que un más bien pacato recelo interpretativo ante su idealismo trascendental. Como consecuencia, se suele entonces intentar sacar provecho de la deducción trascendental en favor de la argumentación prorrealista y se pasa por alto a menudo el papel que desempeña en la concepción del idealismo trascendental.

$15 \mathrm{KrV} \mathrm{A12,} \mathrm{B26.} \mathrm{El} \mathrm{lugar} \mathrm{donde} \mathrm{Kant} \mathrm{expresa} \mathrm{del} \mathrm{modo} \mathrm{más} \mathrm{claro}$ la diferencia entre este sentido de trascendental y el sentido de trascendente son los Prolegomena (A204, nota): "la palabra trascendental no significa algo que va más allá de toda ex-periencia, sino algo precisamente que (a priori) la antecede, pero que no está sin embargo determinado a nada más que a hacer simplemente posible el conocimiento de la experiencia". Cuando, por el contrario, nos las vemos con ideas que "rebasan la experiencia, entonces su uso se llama trascendente, que se distingue del uso inmanente, esto es, reducido a la experiencia". 
uso del calificativo "trascendental" y a aquel uso inestricto del término "deducción".

Con lo que anuncia como "deducción trascendental de los conceptos puros del entendimiento", Kant intenta legitimar el uso empírico de esquemas conceptuales no inducidos de los hechos; o lo que habría de ser lo mismo: la "validez objetiva" de las "condiciones subjetivas" del pensar. La estrategia global de Kant en este punto, más que sus detalles, es lo que nos interesa. ${ }^{16} \mathrm{La}$ aplicabilidad a la experiencia de conceptos y categorías ni extraídos, ni elaborados a partir de la experiencia de un sujeto o de una generación será posible en tanto que la experiencia misma, con su fuerza de constricción - su secondness, en el sentido de Pierce - sólo sea posible a su vez por medio de la articulación combinatoria de conceptos o categorías de esta misma índole. Tenemos, efectivamente, intuiciones sensibles precognoscitivas - todas las recepciones sensibles de un ser vivo que no construya teorías son también de ese tipo-, pero se trataría de hacer patente que las experiencias sobre las que edificamos sistemas de conocimientos empíricos tienen ya, inevitablemente, un preámbulo de qués y de cómos, y que ningún estímulo sensible que recibamos puede tener relevancia cognoscitiva sin tal introito. Los esquemas conceptuales que habrían de ser condición de toda experiencia posible podrían muy bien ser utilizados para pensar objetos imposibles, que nunca aparecerán en la experiencia. Es decir, no se espera que el uso de esos esquemas nos preserve del error. Pero, según Kant, a pesar de la eventual utilidad de esos esquemas conceptuales en la producción de "ficciones arbitrarias y disparatadas", en conjunto ellos han de ser, como condiciones subjetivas del

16 Para nuestros propósitos es importante enfocar la atención sólo sobre esta estrategia y pasar por alto la más problemática adición de Kant de una precisa tabla fija de categorías. 
pensar, condiciones generales de la inapelable experiencia posible. Así pues, se postula, por un lado, que las ficciones pergeñadas con su recurso no serán después de todo puros sinsentidos, sino meramente falsas representaciones, y, por otro lado, que sin su recurso no habrá modo de dar sentido a la representación, atinada o fallida, de la experiencia empírica.

La prueba de que la experiencia misma necesita un previo soporte conceptual, funcionalmente estable y atenido a estos requisitos, la cree encontrar Kant en la "unidad de apercepción trascendental", que no es sino de nuevo la característica unidad de conciencia que acompaña a nuestros variados y sucesivos estados intencionales. "Sólo en tanto que puedo comprender la variedad de las representaciones en una conciencia, las llamo en conjunto mis representaciones, pues en otro caso tendría un yo tan abigarradamente diverso como representaciones, de las que fuera consciente, poseyera." ${ }^{17}$ La unidad del yo, así entendida, es un requisito sintético imprescindible, entonces, para el conocimiento de la realidad exterior. Permite, por ejemplo, que las creencias, así como todo otro estado intencional - esto es, estados mentales dirigidos sobre el mundo-, se formen como todos unitarios, de modo tal que el carácter gradual y articulado, concordante o conflictivo, de cada creencia o cadena de creencias no se disipe en una sucesión desligada. Lo que Kant llama a este propósito categorías del entendimiento son condiciones reguladas del pensar del yo en una experiencia posible; estructuras estables de la conciencia complementarias a las condiciones de la intuición de la experiencia posible (el espacio y el tiempo). El conjunto de elementos y reglas que componen de este modo el armazón de los posibles estados intencionales de un yo preceden a la determinación —a través, por ejemplo, de

$17 \mathrm{KrV}$ B134. 
la investigación científica- de toda específica regularidad o ley natural, por cuanto son condiciones primeras para la agrupación conjuntada de distintas representaciones en la autoconciencia de cada sujeto que acometa una empresa cognoscitiva sistemática. ${ }^{18}$

El meollo del argumento de Kant no es meramente una formulación de la evidencia familiar de que el efecto de los objetos del mundo exterior sobre la conciencia de un ser vivo es una función tanto de la naturaleza de los objetos, como de la estructura del aparato perceptivo del respectivo ser. En este plano disponemos, claro es, de ciertas capacidades perceptivas genéricas que determinan el modo de nuestra relación con el mundo, de la misma forma que otras capacidades determinan otros modos de esa relación en otras especies animales. Más pertinente respecto a la consideración de Kant es, en cambio, la ya también ampliamente reconocida influencia de las creencias previas y las expectativas de cada sujeto en su percepción de los estados de cosas. En conexión con sistemas teóricos específicos este fenómeno toma el mayor relieve. Una misma esquina acotada del mundo exterior se presenta con distinta apariencia en las circunstancias ordinarias de un observador común que sometida a los dictados científicos del análisis de un físico; y lo que éste contempla es distinto, a su vez, de lo que vería en el mismo lugar un biólogo, un psicólogo o un juez. Cada uno de ellos aplica, en el marco de su labor cognoscitiva correspondiente, distintos criterios de relevancia, de manera que lo que ven es dispar, porque es dispar lo que buscan. Sin embargo, como ya he dicho,

18 "Hay muchas leyes de la naturaleza que sólo podemos conocer a través de la experiencia, pero no podemos llegar a conocer por medio de ninguna experiencia el ajuste a leyes de la conexión de las apariencias, esto es, la naturaleza en general, porque la experiencia misma requiere de tales leyes, que son fundamento a priori de su posibilidad." Prolegomena, Alll. 
en su deducción trascendental Kant no alude en realidad tampoco a sistemas conceptuales específicos, del tipo de los que asociamos a cada región científica demarcada, sino a sistemas conceptuales que habrían de subyacer en toda empresa cognoscitiva empírica humana. ${ }^{19}$ Cuando estamos ensimismados tenemos percepciones visuales o auditivas que no reconocemos. Es precisamente al reconocimiento de estas percepciones a lo que Kant llama experiencia. ${ }^{20}$ En términos kantianos, tal experiencia es únicamente posible cuando las percepciones son recibidas con una atención de nuestra conciencia que engendra apetitos, creencias, designios, alarmas... Toda experiencia perceptiva tiene, en

19 Naturalmente, no quiero sugerir con esto que fuera de los lugares de confluencia de órbitas científicas no se dé una confrontación de criterios de relevancia, como cuando se ventila, por ejemplo, si lo que alguien hace en una ocasión dada es imitar muy bien a un gorila o asustar al niño.

Ciertas tesis ontológicas actuales, que se autocalifican como kantianas, basan el fundamento de su posición en lo abigarrado de la realidad a la que se accede - en virtud de respectivos criterios de relevancia - a partir de esquemas conceptuales regionales diversos. La "regionalidad" a la que se alude no tiene especial sello personal, ni tampoco forzosamente la circunstancialidad de un hábito social o tradición comunitaria particular. Las lindes regionales que se tienen a la vista son más bien, precisamente, las que demarcan a las distintas ciencias entre sí, o a la ciencia del sentido común, de la filosofía, o de la moral; o ésas que dibujan distintos apartados dentro de estos territorios siguiendo la línea de pertinencia que está marcada por un rumbo conversacional o de disputa (como cuando, por ejemplo, la causa pertinente de la explosión de una caldera es un defecto de su válvula de seguridad, más bien que el obstáculo que cualquier otro punto de la superficie de la caldera ofrece también al escape de vapor). Entre esta fórmula de relatividad conceptual y la generalidad del esquema conceptual que la deducción trascendental intenta respaldar no hay ningún conflicto de principios, sino que, al contrario, esta deducción pretende en cierto modo parificar las condiciones del marco conceptual que permite determinar que aquélla relatividad o irreductibilidad conceptual no es adventicia, sino imperiosamente racional.

$20 \mathrm{KrV}, \mathrm{B} 147$. 
este sentido, una carga conceptual, depositada en lo que podríamos llamar su intencionalidad..$^{21}$

Las experiencias perceptivas comprenden intencionalidad en cuanto que tienen contenido proposicional y condiciones de satisfacción que están dispuestas en el sentido de su contenido proposicional. ${ }^{22}$ Una creencia puede ser falsa, pero la determinación de su falsedad requiere la previa determinación de su sentido. Análogamente, una experiencia perceptiva puede ser una alucinación, pero el contenido proposicional de tal experiencia fija las condiciones que, de

21 Como es bien sabido, la noción de intencionalidad está asociada a la filosofía de Brentano y a la fenomenología. Ahora bien, aquí empleamos la noción en una acepción parca. Un estado intencional es un estado mental dirigido sobre el mundo. Así pues, son estados intencionales tanto las meras intenciones o propósitos, como las creencias, deseos, expectativas, temores, etc. Las experiencias conscientes del mundo unificadas por un yo a las que Kant alude repetidamente son estados intencionales. A partir de ahora, nuestro uso del predicado "intencional" estará asociado a este sentido general, mientras que dejaremos el predicado "intencionado" asociado al sentido restringido ordinario del término intención. Como una intención es un específico estado intencional, una acción intencionada, p. ej., es también una acción intencional.

22 Vid. John Searle, Intentionality, op. cit., pp. 37-79. Sin embargo, ahora y en lo que inmediatamente sigue nos alejamos de la posición de J. Searle en un extremo capital. Searle —al igual que Roderick Chisholm - sostiene que los estados intencionales anteceden al lenguaje. La antecedencia absoluta de los estados intencionales sobre los actos de habla estaría acreditada por nuestra atribución de estados intencionales a niños pequeños y a animales. Ahora bien, una imaginable antecedencia genética de esta índole no entraña una antecedencia lógica, toda vez que el contenido de esos estados intencionales no puede ser sino el contenido de lo que, como intérpretes, concebimos como el contenido de una interpretación (el contenido de un conjunto de actuales o posibles actos de habla). Esto no entraña a su vez una antecedencia lógica del lenguaje respecto a los estados intencionales, porque todo acto de habla no defectivo está secundado por un estado intencional. Al respecto, no hay pues "antecedencia lógica" ni en una dirección, ni en otra. La aplicación de un giro lingüístico a la filosofía kantiana no altera por eso capitalmente el carácter del núcleo de sus tesis. 
ser cumplidas, hacen verídica esa experiencia. En contrapartida, si no somos capaces de atribuir a una proposición con contenido de pretensión empírica condiciones de satisfacción, o de dar a un concepto un uso ajustado en el seno de proposiciones con sentido, esa proposición y ese concepto serán ensoñaciones metafísicas. La parte esencial de la metafísica tendría, en efecto, que ver, según Kant, "con puros conceptos de razón, que nunca se dan en ninguna experiencia; con conceptos, pues, o con afirmaciones cuya, respectivamente, realidad objetiva (puesto que sólo son fantasmas mentales) o verdad o falsedad no puede ser confirmada o denunciada por experiencia alguna". ${ }^{23}$ Representaciones sin sentido son aquéllas para las que no cabe imaginar ni una recusación, ni un respaldo de la experiencia. Mas la intelección nuclear sobre la que se concentra la deducción trascendental es la primera complementaria de que, a su vez, toda experiencia empírica - por tanto, también las que sirven de criterio para la confirmación o denuncia de otras representaciones - es únicamente posible en tanto que tiene un contenido proposicional; es decir, en tanto que tiene sentido. ${ }^{24}$

La posición filosófica que deniega a las experiencias perceptivas una inevitable articulación conceptual puede intentar consolidarse poniendo de manifiesto las diferencias que median entre tales experiencias y las creencias que

23 Prolegomena, A125. A este criterio kantiano de discriminación de opiniones metafísicas lo ha denominado Peter Strawson "principio de significación" en Los límites del sentido.

24 Ortega y Gasset, a su estilo, ha visto muy bien la complementariedad entre el realismo empírico y el idealismo trascendental (entre la "refutación del idealismo" y la "deducción trascendental"). Las ocasionales denostaciones antikantianas de Ortega están dirigidas al Kant petrificado de la escuela de Marburgo, pero su concepto de "razón vital" acoge cordialmente al complementado matrimonio que forman ese realismo y ese idealismo. Cfr. su "Anejo a Kant", en Kant-HegelScheler, Revista de Occidente, Madrid. 
asociamos a los actos de habla, o las creencias generales no vinculadas a percepciones inmediatas. Algunas de estas diferencias son notorias. Una experiencia perceptiva, en el sentido en que la hemos definido, es necesariamente consciente, mas no toda creencia es consciente. Por otro lado, tenemos ocasionalmente claras experiencias perceptivas a las que, pese a su claridad, contraponemos creencias. Si introducimos un palo recto en el agua, lo vemos claramente doblado, pero no creemos que esté doblado. Una primera creencia clara a la que contrapongamos luego otras creencias incompatibles deja en cambio de ser, cuando menos, tan clara. Por último, tal vez sea dudoso que una experiencia perceptiva tenga un contenido genuinamente representativo, toda vez que las creencias representan estados de cosas que no están necesariamente a la vista, pero una experiencia perceptiva verídica da en cambio por asentada la presencia inmediata de los objetos de experiencia. Estas diferencias podrían tal vez sugerir que si las creencias están envueltas por una tupida red conceptual, las experiencias perceptivas genuinas pueden por el contrario carecer de tal envoltorio y que sólo, acaso, las experiencias fantásticas o engañosas, en tanto que no son causadas por el estado de cosas del que la experiencia pretende ser experiencia, tienen un contenido conceptual, insuflado por el sujeto. Sin embargo, esta hipotética alegación no puede contender seriamente contra el decisivo hecho de que toda experiencia perceptiva, en cuanto que no es ensimismada, sino precisamente consciente o intencional, no es mera experiencia de algo, sino de que algo es - o parece ser- el caso. Es decir, nuestras experiencias perceptivas están articuladas proposicionalmente y esta articulación es, precisamente, la medida de su conceptualización.

El contenido de una experiencia puede, ciertamente, ser mínimamente informativo, pero toda experiencia requiere algún contenido, en gracia al cual determinamos que he- 
mos experimentado lo que hemos experimentado. Aun en el caso extremo de la experiencia de algo desconocido, cuya naturaleza exacta ni siquiera barruntamos, experimentamos algo como algo. Por ejemplo, precisamente algo que nosotros hemos percibido, algo que no reconocemos, algo que es diferente a todo lo que reconocemos, algo que encontramos, o apareció, en algún lugar y momento, tal vez algo que nos conturbó, etc... A su vez, decimos que una experiencia es fantástica o engañosa sólo cuando no hay ningún estado de cosas que corresponda al contenido proposicional de esa experiencia y que sea causa de la misma experiencia. Ni una formulación de confianza, ni una de duda son expresables si no engarzamos nuestra percepción con un sentido. Si la mesa que veo delante de mí es una quimera, será porque no hay un hecho que dé cuenta de que esa mesa está delante de mí. Nada puede convencer o desengañar a Segismundo de estar en un palacio suntuoso, entre telas y brocados, que no sancione o conteste a la proposición de que Segismundo está en un palacio suntuoso, entre telas y brocados. La confrontación, a su vez, entre experiencias perceptivas - ya sean claras o difusas - y creencias generales es sólo factible en tanto que los contenidos proposicionales de unas y de otras abren la vía de la conmensurabilidad mutua. El entretejimiento lingüístico de nuestras experiencias perceptivas no anula, en cualquier caso, las disimilitudes iniciales anotadas con las creencias. Las experiencias perceptivas sólo se transmutan en un tipo de creencia cuando son secundadas por pretensiones de validez. En ese momento, lo más peculiar de tales creencias respecto a otras creencias es que, para que su pretensión sea satisfecha, el estado de cosas correspondiente a su contenido proposicional tiene, primero, que existir y, segundo, ha de ser la causa de la propia experiencia. En esta medida, las condiciones de satisfacción de una experiencia perceptual son peculiarmente 
autorreferenciales. ${ }^{25}$ Para determinar que la experiencia es verídica no cabe omitir la referencia a la experiencia misma, como efecto causado del estado de cosas que su contenido proposicional representa. Tengo una percepción visual de que llueve no sólo si efectivamente llueve, sino si veo, como efecto causal precisamente de ese estado de cosas, y no de otro, que llueve. En dicha relación causal se concentra el aspecto constrictivo de nuestras experiencias y, por otro lado, ésa es una relación únicamente posible con la trabazón proposicional que articula las experiencias.

\section{$\mathrm{V}$}

La misma conformación intencional que articula las experiencias perceptivas, articula propiamente la entera generalidad de los hechos. No hay hecho determinable alguno que no sea correlato de una proposición, contenido de un eventual estado intencional. Como el sentido de una proposición verdadera está además perfilado por el sentido de cada proposición falsa que la contradice, el correspondiente hecho se articula tanto a través de, por ejemplo, una eventual creencia atinada, como de las posibilidades irrealizadas manifiestas en ciertas otras creencias falsas, o en intenciones o deseos imaginables. El hecho sólo se constituye en la medida en que puede satisfacer a un estado intencional y contravenir a otros. Algunos filósofos, en cualquier caso, contraponen a la afección intencional de los hechos, o de las experiencias perceptivas complejas, una ontología extraintencional de objetos referenciales. Tales objetos serían identificados con independencia de los contenidos a ellos asociables, básicamente tan sólo en virtud de una relación causal, desembarazada de toda descripción precisa, entre el correspondiente objeto y nosotros. La contraposición de

25 Vid. John Searle, op. cit., pp. 48-50. 
esta tesis a las tesis sostenidas por las teorías descriptivistas de la referencia es, en términos ontológicos, una contraposición al idealismo trascendental.

Para referirse a un objeto es preciso disponer de una identificación de ese objeto. El objeto sólo es realmente denotado si es identificable. El que se conoce como punto de vista descriptivista en teoría de la referencia viene a parar en que esa identificación involucra estados intencionales y que ello compromete así la expresión de posibles proposiciones verdaderas y, por ende, de hechos. El propósito del hablante de identificar un objeto preciso, así como el reconocimiento de sus interlocutores del fin de tal propósito, son subsidiarios de estados intencionales. Estados intencionales, y sus correspondientes contenidos proposicionales, estarían ligados tanto a procedimientos de identificación por medio de descripciones definidas, como a procedimientos de identificación ostensivos o demostrativos. La conexión entre una descripción identificadora definida y un estado intencional es clara: el contenido del estado intencional requerido es la proposición que atribuye el contenido de esa descripción al objeto referido. A su vez, dijérase que la denotación de un objeto por medios puramente ostensivos (un gesto de la mano, un demostrativo...) está tácitamente enlazada a términos descriptivos y, por lo tanto, a atributos. Así, por ejemplo, hablando de mesas identificamos a "ésa" porque suponemos las condiciones de aplicación del predicado "ser una mesa", al igual que las de otros predicados como, tal vez, "estar en el campo visual inmediato del hablante", "ser el único objeto que cumple la descripción dada dentro de ese campo visual", etc. En rigor, la función identificadora de la denotación se cumple, o se trunca, sólo en tanto que algunas de esas descripciones sean verdaderamente atribuibles, o no lo sean, al objeto que se intenta denotar. La noción de verdad de una 
proposición, o la de satisfacción de un estado intencional, ha de anteceder a la noción de referencia. ${ }^{26}$

Los argumentos de esta clase se pueden extender con aparente facilidad. La moraleja central del tópico de la "inescrutabilidad de la referencia" establece que los objetos referidos son precisamente irredimibles feudatarios de las condiciones proposicionales de verdad dentro del todo de un lenguaje. Una referencia que anteceda a toda precisión articulada de condiciones veritativas está rodeada de un impenetrable halo de indeterminación. Mas con todo, ciertas teorías de la referencia han insistido en conceder expresamente a los objetos referidos mismos, respecto a todo sistema de proposiciones o creencias, o procedimiento descriptivo, una autonomía que pone en entredicho la oportunidad de una reconstrucción del núcleo de la deducción trascendental a través de las líneas que hemos bosquejado. Haré mención de dos enjundiosas y veneradas de sus muestras.

En relación con las descripciones definidas, Keith Donnellan ha pergeñado una ya clásica dicotomía conceptual que, a) cuestiona el sentido de una referencia en la que una ostensión indescriptiva no sea el componente cardi-

26 Éste es el sentido en el que el meollo de las llamadas teorías descriptivistas de la referencia se acomoda con naturalidad a las representaciones holistas del lenguaje. Cfr. D. Davidson, "Reality without Reference", en Inquiries into Truth and Interpretation, Clarendon Press, Oxford, 1985, pp. 215-227.

La sección que, a mi juicio, tiene más interés en la versión de la deducción trascendental que propone Dieter Henrich en su Identität und Objektivität (C. Winter, Heidelberg, 1976, pp. 16-54) es justamente la que se hace eco de los argumentos de las teorías descriptivistas de la referencia. Dieter Henrich, sin embargo, no acaba de sacar partida cumplida de estos argumentos, toda vez que insiste en intentar sacar punta filosófica a una inescrutable antecedencia de la autoconciencia "pura" sobre la conciencia del hablante. Cfr. también Dieter Henrich, "Was ist Metaphysik - Was Moderne? Zwölf Thesen gegen Jürgen Habermas", en Konzepte, Suhrkamp, Frankfurt, 1987, pp. 11-44. 
nal y, b) determina un modelo especial de referencia sin componentes descriptivos, del que afirma que cumple una función análoga a la de los nombres lógicamente propios russellianos: la de hacer referencia a algo sin una asignación de propiedades. La dicotomía en cuestión es la establecida entre el uso referencial de las descripciones definidas y su uso atributivo. ${ }^{27}$ Según Donnellan, un hablante usa atributivamente una descripción definida si asevera algo acerca de que una entidad cualquiera es tal-y-tal. Por el contrario, la emisión de una descripción definida tiene un uso referencial si tal descripción es empleada como mero instrumento para llamar la atención de los oyentes sobre entidades concretas. Donnellan ha proporcionado el siguiente ejemplo ilustrativo. Considérese la oración (i) "El asesino de Álvarez está loco". Supongamos que (i) es emitida aseverativamente por alguien que no sabe quién es el asesino de Álvarez, pero que, conociendo las circunstancias particularmente violentas del hecho criminal, cree que nadie, sino un loco, puede haber llevado a cabo el truculento asesinato del bueno de Álvarez. Éste es el uso atributivo de la descripción definida "el asesino de Álvarez". Si, por el contrario, Fernández ha sido acusado de ese asesinato y durante la vista de su proceso un observador, a tenor de la extravagante conducta de Fernández en la sala, emite (i), tenemos un uso referencial de la misma descripción definida. Si en realidad Álvarez no fue asesinado, sino que, por ejemplo, se suicidó, este hecho contradice presuposiciones de ambos usos, pero en cada caso las consecuencias que de ello se derivan son distintas. En el uso atributivo no existe en tal situación ninguna persona a la que se atribuya locura. Únicamente si la descripción definida se acomoda a alguien, la emisión atributiva de (i) puede ser verdadera

27 Keith Donnellan, "Reference and Definite Descriptions", en Philosophical Review, LXXV, 1966, pp. 281-304. 
o falsa. Sin embargo, bajo las mismas condiciones el uso referencial de "El asesino de Álvarez" en la emisión de (i) es un procedimiento eficaz para identificar a Fernández y para afirmar algo verdadero, o falso, acerca de él, aun cuando esa descripción no convenga a Fernández. En esta ocasión se hace referencia a Fernández, aunque Fernández no sea el asesino de Álvarez, y se dice algo, verdadero o falso, de él.

"Generalizando a partir de este caso - concluyó Donnellan - pienso que podemos decir que hay dos usos de oraciones de la forma ' $\mathrm{El} \phi$ es $U$ '. En el primero, si nada es el $\phi$, entonces de nada se ha dicho que sea $U$. En el segundo, el hecho de que nada sea el $\phi$ no tiene esa consecuencia." 28 Quien emite una oración del tipo "El $\phi$ es $U$ " dando un uso atributivo a "El $\phi$ " en circunstancias en las que no hay nadie o nada que sea $\phi$, no dice de nadie ni de nada que sea $U$. Pero si el uso de "El $\phi$ " es referencial y nadie o nada es $\phi$, cabe no obstante muy bien la atribución de $U$ a alguien o algo - justamente a aquello a lo que se ha referido. Si alguien afirma respecto a la señora López, presente ante nosotros, que (ii) "su marido es muy atento con ella", dando a "su marido" un uso referencial que llama nuestra atención sobre Rodríguez, que está en ese momento galanteando con la señora López y que no es su marido, sino su amante, se habrá dicho algo que es verdadero justamente de Rodríguez.

La dicotomía de Donnellan es inobjetable. El punto problemático es su apreciación; en particular, su caracterización del uso referencial. Según la vieja posición de Russell, los nombres propios ordinarios tienen connotación y, en tal medida, se pueden expresar en los términos de la teoría de los descriptores; la connotación que acompaña al nombre propio ordinario es una propiedad predicable. Los nom-

28 Op. cit., pp. 286. 
bres lógicamente propios —una idealización irrealizada en el lenguaje ordinario - serían, en cambio, exclusivamente aquéllos que hacen referencia a la cosa misma sin componente descriptivo alguno $\mathrm{y}$, al fin y al cabo, libres de contenido intencional. Pues bien, Donnellan ha opinado que ésta es la labor real que cumple justamente el uso referencial de las descripciones definidas. Y, entonces, este concepto "parece dar un sentido en el que tenemos que ver con las cosas mismas, y no con las cosas bajo una cierta descripción." 29

Aparentemente, en el uso referencial de una descripción definida se produce una disparidad entre la referencia que considera el hablante y la referencia que literalmente identifica la expresión caracterizadora ("referencia semántica", la ha llamado Kripke). La disparidad entre el significado literal de una emisión y el significado de la emisión “del hablante" afecta igualmente a todos los actos de habla metafóricos, irónicos e indirectos. Ahora bien, en la realización de tales actos es la forma de la disparidad misma la que vertebra a la propia intención metafórica o irónica y a los distintos matices ilocucionarios de las emisiones indirectas. Después de todo, para dar a entender ahí el acto de habla que se ha querido realizar, se ha tenido que decir lo que se ha dicho. ${ }^{30}$ En el uso referencial de una descripción defini-

29 Idem., p. 303. Cfr. igualmente las sugerencias de Donnellan en "Speaking of Nothing", en Naming, Necessity, and Natural Kinds, S.P. Schwartz (comp.), Cornell University Press, Itaca (N.Y.), 1977, pp. 216-245, passim. Dos palabras para destacar el extremo capital a este respecto: la tesis subrayada de Donnellan no se aviene con la versión de deducción trascendental esbozada, toda vez que los estados intencionales (creencias, dudas, intenciones...), que - decíamosconstituyen la experiencia, tienen un contenido proposicional y las descripciones definidas, como ya hemos sugerido, son parafraseables en forma proposicional (es decir, son posibles contenidos intencionales).

30 Como con usos literales de las palabras no podemos crear metáforas, o mostrar nuestro ingenio cáustico o nuestra mesurada educación, 
da desatinada, la disparidad en cuestión puede ser también intencionada. Mas lo común, por el contrario, es que el hablante no busque la disparidad. Como no obstante, en los ejemplos de Donnellan, su auditorio no tiene graves dificultades para reconocer el objeto referido, ello acreditaría que hay un nivel comunicativo primario - acaso base última de todos los demás - en el que calamos a las cosas mismas sin la red de esquema conceptual alguno. La "referencia del hablante" de una descripción definida es el objeto del que el hablante quiere hablar en una cierta ocasión y del que cree que se ajusta a las condiciones de satisfacción de la referencia "literal" o "semántica". En el ejemplo (ii), tal sería el amante de la señora López, mientras que el marido de la señora López sería la referencia semántica. En el uso atributivo "serio y literal" de las descripciones definidas no puede haber divergencia entre una referencia y otra; pero sí puede haberla en un uso referencial análogo.

El punto clave que arrumba la especial sugerencia sustancialista abrigada en todo esto es el siguiente: cuando en el llamado uso referencial la referencia del hablante y la referencia semántica no coinciden, el hablante puede realizar la función identificadora de referir sólo en cuanto que exista la posibilidad de reformular la referencia semántica de tal modo que se acomode a la intención referencial del hablante y mantenga, al tiempo, un lazo familiar con la primera formulación. Así, después de todo, también aquí hay una conexión entre lo que literalmente se dice y lo que la audiencia llega a entender. Para interpretar la intención referencial del hablante, sin desorientarse con la falsa asignación de propiedades, la audiencia ha de imaginar un contenido descriptivo que califique adecuadamente un objeto y que corrija de modo pertinente la primera des-

a esos fines dejamos intencionadamente entender un tropo en la literalidad de lo que decimos. 
cripción desacertada. La descripción definida inadecuada no puede ser inadecuada de cualquier modo, sino de un modo que guíe a su misma corrección. $\mathrm{Si}$, por el contrario, no existe ninguna reformulación descriptiva familiar que pueda rellenar pertinentemente el vacío denotativo de una primera descripción definida, no se habrá hecho referencia: nada habrá sido identificado. Éste sería el caso en el uso referencial de (i) si no sólo ocurriera que nadie ha asesinado a Álvarez, sino que tampoco nadie hubiera sido acusado de hacerlo, o nadie, aparte del hablante, sospechara que cierta persona lo ha asesinado. Lo que se realiza a través del uso referencial de un signo lingüístico no es simplemente algo que podría realizarse con independiencia de todo uso de signos lingüísticos, al margen de todo sistema articulado de representaciones. ${ }^{31}$ En comparación con el uso referencial, lo único característico del uso atributivo es que no dispone de procedimientos descriptivos subyacentes explicitables: si a la descripción definida original le corresponde un vacío denotativo, no hay arreglo posible.

\section{VI}

Se ha cavilado también que, si bien las descripciones definidas envuelven la representación de propiedades de los objetos y, con ello, contenidos proposicionales, los nombres propios ordinarios en realidad se relacionarían con el objeto que identifican con independencia básica de las connotaciones caracterizantes que siempre acompañan a su uso. El grado de intencionalidad del que están cargados sería, después de todo, un extremo secundario. Si las características que asociamos a los nombres no fueran contingentes, cualquier descripción verdadera habría de ser una defi-

31 Ésta es una idea que Ernst Tugendhat patrocina vigorosamente en sus Vorlesungen zur Einführung in die sprachanalytische Philosophie, Suhrkamp, Frankfurt, 1979; particularmente, pp. 476-484. 
nición analítica, y cualquier descripción falsa una contradicción. Aristóteles fue maestro y discípulo de Platón, pero podría no haber sido ni lo uno, ni lo otro. ¿Diríamos en esas circunstancias contrafácticas que el nombre Aristóteles no designa a ninguna entidad? La carga descriptiva de los nombres propios tiene, sin embargo, ciertos fundamentos familiares. Una primera descripción elemental acompaña al tipo del nombre; el género de aquello de lo que el nombre propio es un nombre propio: personas, islas, caballos... Y la presuposición del vínculo entre cada nombre y una serie imprecisa de otras propiedades estaría incorporada, igualmente, a los enunciados de identidad y a las proposiciones existenciales. Si los nombres tuvieran exclusivamente denotación, resultaría extravagante conceder un valor de verdad a los enunciados existenciales negativos. Por eso en la correspondiente perífrasis de raíz russelliana el nombre propio se convierte, por el contrario, en parte predicativa dentro de una cuantificación existencial negativa. Se entiende que el buen sentido de este artificio (independientemente de otras polémicas cuestiones) es un resultado del contenido descriptivo ligado al nombre. En todos los casos en que no se formula una identidad tautológica, la determinación de la identidad de objetos denotados por distintos nombres propios resulta jugosamente informativa merced también, precisamente, a diferencias connotacionales. Cuando llegamos a saber que Lorenzo Gracián fue Baltasar Gracián añadimos una información a la vacía identidad de "Baltasar Gracián es Baltasar Gracián". Lo que añadimos, por ejemplo, es la información de que el pacato autor de "El comulgatorio" es el cáustico autor de "El oráculo manual". Ahora bien, se arguye que el conjunto de estas alegaciones "descriptivistas" choca, empero, con la mencionada contingencia aparente de las calificaciones descriptivas del objeto denotado por cada nombre propio. 
Frente al modelo descriptivista general, y en defensa de las tesis básicas de Stuart Mill al respecto, han sido elaborados diversos ensayos de una teoría puramente denotativa de la referencia de los nombres propios. El ensayo de este género más sutil y sugestivo es probablemente el forjado por Saul Kripke. ${ }^{32}$ La vía argumentativa de Kripke compromete una distinción radical entre epistemología y metafísica y una aplicación de la noción de necesidad restringida al ámbito conceptual de la metafísica. Esa dicotomía se desliza dentro de una forma de sustancialismo de objetos nominados muy opuesta al sentido de la deducción trascendental. La teoría de la referencia descriptivista genera, desde luego, insuperables inconvenientes si pretende ligar a cada nombre propio, como expresión sinónima, una lista fija de descripciones definidas. Gödel, "el autor del teorema del mismo nombre", seguiría nombrando a Gödel aun cuando se revelara que no es el autor real del teorema que prueba la incompletud de la aritmética, sino un vulgar plagiario. La solución descriptivista a este engorro ha de descartar un vínculo necesario entre cada objeto nombrado y una serie fija de descripciones asociadas, y conectar el sentido de los nombres propios, requerido para cumplir su función de identificación, a las descripciones del tipo del objeto y a un abanico indeterminado de descripciones contingentes. Si se revelara documentalmente que Aristóteles no era natural de Estagira, Aristóteles designaría aún el mismo objeto antes y después de la revelación. Pero la determinación del tipo paraliza ciertas revelaciones. ¿Cómo podría "revelarse" que Aristóteles era en realidad un caballo percherón o una mazorca de maíz? En rigor, esto arrastra ya consigo la exclusión de la contingencia del conjunto

32 Saul Kripke, Naming and Necessity, Blackwell, Londres, 1980. [Trad. castellana: El nombrar y la necesidad, Trad. de Margarita M. Valdés, Dirección General de Publicaciones, UNAM, México, 1985.] 
de las suplementarias descripciones familiares connotadas por un nombre efectivamente denotativo. Para identificar con un nombre propio a algo no sería necesario, entonces, que cada descripción familiar correspondiera a la entidad denotada por el nombre, pero sí que lo haga una parte indeterminada y no autocontradictoria de la suma lógica de tales descripciones. No es forzoso que esa parte sea mayoritaria, pero sí que posea una especial pertinencia, que garantice una notable univocidad en la identificación intersubjetiva de la entidad nombrada en el curso de la alteración de las propiedades atribuidas a dicha entidad.

La porción saliente de la exposición del argumento de Kripke, en cambio, se concentra en una versión de descriptivismo en la que el acento marcante se situaría en la conexión de cada nombre propio con una parte mayoritaria e inquebrantable de ese conjunto descriptivo. En cualquier caso, lo que puede inhabilitar a dicho argumento no es simplemente que perpetre este pequeño retruécano que violenta a su rival. Ese argumento sostiene aún, en su punto más radical, que incluso si todas las descripciones agavilladas alrededor de un nombre propio fueran falsas, tal nombre propio no perdería su vigor denotativo. Los nombres propios serían, en contraste con lo que sucedería con una gran parte, al menos, de las descripciones, designadores rígidos. Un designador sería rígido si, ya hubiere pasado lo que hubiere podido pasar, y llege a pasar lo que puda pasar, siempre designa el mismo objeto; y sería no rígido o accidental si no es así. El número 9 sería un designador rígido, pero "el número de los planetas" sería un designador accidental. Igualmente, "el vencedor de las elecciones españolas de 1987" sería un designador accidental; "Felipe González", un designador rígido. Con esta dicotomía conecta Kripke una división entre propiedades esenciales y accidentales. Felipe González podría no haber sido el vencedor de esas elecciones y, con este criterio, "ser el vencedor 
de las elecciones españolas de 1987" es una propiedad accidental. Por el contrario, Felipe González no podría dejar de ser Felipe González. Así, de modo análogo a como según el realismo empírico kantiano los objetos han de preservar cierta unidad sustancial a través de sus cambios en el transcurso del tiempo, habrían de preservar también esa unidad a través de todo imaginable cambio contrafáctico. En realidad, la misma unidad sustancial presupuesta de uno y otro caso - por medio de las sucesivas vicisitudes mundanas, o mediante nuestras representaciones imaginativas e hipotéticas - exhibe la irreductible función de los nombres propios en el lenguaje y su irrelegabilidad en favor de puras descripciones momentáneas o fácticas.

¿Mas implica esto un sustancialismo contrario al núcleo de la tesis descriptivista? No, porque, primero, esta tesis, como decimos, no reduce los nombres propios a listas cerradas de descripciones - ésa es la razón de la indeterminación global del conjunto de las descripciones vinculables a cada nombre. Y porque, segundo, tal tesis descriptivista no contraviene el presupuesto de real y contrafáctica unidad sustancial: todo lo que esa tesis afirma es que para traer a colación a esas sustancias - para decir, por ejemplo, algo verdadero o falso acerca de ellas - son requeridos los medios de identificación que provee el uso de designadores, y que los diferentes designadores sólo cumplen esa función en el seno de un lenguaje completo. Si, al intentar con un nombre identificar un objeto ausente, son segadas absolutamente todas las descripciones que eventualmente connota el empleo de tal nombre, segregándole así del conjunto entero de la malla lingüística, con tal "nombre" no se identificará nada a nadie. Y si el nombre —omitiendo su carga connotativa acumulada - es usado a modo de demostrativo, frente a frente con la entidad nombrada, el nombre tendrá el lastre proposicional que tienen todas nuestras experiencias perceptivas intencionales. Nuestros 
nombres propios usuales de objetos reales designan entes asequibles: precisamente los identifican. En esa medida carece de sentido imaginar que todas las descripciones que le son atribuibles espontáneamente a un objeto real nominado sean falsas a un tiempo. Algunas han de ser verdaderas: las precisas para identificar al objeto nombrado y, eventualmente, determinar así que las restantes son falsas, o que cada una de ellas podría serlo. ${ }^{33} \mathrm{Y}$ una situación paralela se da cuando el nombre dado no designa un ente existente: la intención identificadora manifiesta a través de su expresión resulta insatisfecha sólo en tanto que no puede ser satisfecha ninguna - o una parte especialmente relevante- de las descripciones identificadoras connotadas. ${ }^{34}$

\section{VII}

Si tomamos ahora en cuenta la articulación proposicional de nuestros estados intencionales generales y cómo éstos condicionan nuestras experiencias perceptivas, la determinación de hechos y la identificación de objetos, las ideas conectadas a la argumentación kantiana de la deducción trascendental se hacen reformulables en términos muy familiares. La denominada unidad de los objetos de la expe-

33 En realidad la misma obra de Kripke está comprometida con sugerencias "descriptivistas". Por ejemplo, a través de su representación de una fijación bautismal descriptiva de la referencia; a través de la estipulación de intenciones sucesivas de los hablantes de designar con un nombre al mismo objeto que hablantes anteriores de la cadena de comunicación designaron con ese nombre; y a través del reconocimiento (extrañamente parapetado en un sustancialismo cientificista) de propiedades esenciales en los objetos nombrados.

34 Adviértase que propiamente esta última observación no sólo es pertinente en el caso de que el hablante intente identificar objetos reales, porque bien cabe identificar un objeto fantástico, o fallar en el intento, si es eso lo que se pretende: por atención justamente a las propiedades que lo caracterizan en el mundo de ficción ("Ulises, el astuto griego de la Odisea"). 
riencia, entendida como producto de la actividad cognoscitiva - regulada por categorías - de la conciencia unitaria de cada sujeto, debería simplemente ser equiparada a la consecuencia uniformadora que es sugerida de modo natural, primero, por la dependencia de la interpretación de cada proposición individual respecto a un lenguaje entero ya constituido y, segundo, por la dependencia de la interpretación de cada componente proposicional respecto a proposiciones completas. Otros puntos claves de la constelación temática kantiana pueden fácilmente adquirir así un nuevo acento sin perder fidelidad histórica. La misma idea de "entendimiento universal", tan íntimamente unida a los desvelos de Kant como invocación compendiadora de condiciones subjetivas generales del conocimiento de hechos y cosas, sería ahora acomodable dentro de los márgenes de una posible unidad de interpretación del lenguaje. La mínima región imprescindible de traducibilidad intersubjetiva e interidiomática se convertiría, entonces, en la más elemental armazón categorial de la experiencia posible. Paralelamente, las sucesivas viejas polémicas antikantianas impulsadas por un aliento historicista tenderían ahora a agruparse alrededor de alguna forma de relativismo lingüístico. Por último, el intríngulis del idealismo trascendental bien podría plasmarse en la intelección sucinta de que la verdad es una propiedad de proposiciones, cuya correcta atribución a cada proposición sólo cabe determinar con el recurso de otras proposiciones. Esto implica que si bien el contenido de cada creencia empírica (incluyendo las asociadas a nuestros procedimientos de identificación de objetos) es correcto o incorrecto en atención a los hechos, propiamente no hay hecho alguno al que accedamos sin ningún recurso lingüístico. La autonomía de los hechos y los objetos respecto de cada creencia de cada sujeto está respaldada, claro es, por el realismo empírico y, en compatibilidad con ello, su peculiar dependencia respecto al lenguaje (un 
sistema de infinitas proposiciones) está respaldada entonces por el idealismo trascendental. ${ }^{35}$ De acuerdo con esta definición, el idealismo trascendental no defiende que nuestros lenguajes o esquemas conceptuales específicos sean inmutables y que no haya ahí espacio, por consiguiente, para alteraciones importantes. Pero sí defiende que todo cambio de este género, que abra nuevas condiciones de sentido y,

35 El tipo de realismo con el que, por el contrario, el idealismo trascendental colisiona es ese realismo lógico (realismo trascendental lo llamó Kant) que afirma la independencia de los hechos respecto del lenguaje.

Algunas de las más actuales embestidas filosóficas antikantianas, confundidas en cierta medida por el sobreacento realista puesto por algunas de las modernas interpretaciones del pensamiento de Kant (vid. supra, n. 15), se dirigen a la superación de disyunciones como las de conceptos/intuiciones, esquemas/contenidos, lenguaje/realidad, sujeto/objeto, etc... precisamente sobre la base de algún género, más o menos nítido, de antirrealismo lógico. Justamente porque no tienen a la vista esta complementariedad capital entre el realismo empírico y el idealismo trascendental, arman pendencia contra tales disyunciones, que son perfectamente inocentes - y en rigor imprescindibles- una vez asentada dicha complementariedad. Como botón de muestra de este antikantismo - guarnecido en este caso con ribetes historicistasvéase el artículo de Richard Rorty, "Transcendental Arguments, SelfReference, and Pragmatism", en Transcendental Arguments and Science, P. Bieri, R.P. Horstmann y L. Krüger (comps.), Reidel, Dordrecht, 1979, pp. 77-105.

Dicho sea ahora de paso. Una vez esbozados los principios para una reconstrucción lingüística del idealismo trascendental, es fácil ver que aquellas experiencias que estaban en la base de los argumentos a favor del realismo empírico están estructuradas en los usos más constitutivos del lenguaje. La experiencia del encuentro del mismo persistente objeto (diferenciado del encuentro sucesivo de diferentes objetos idénticos, tan efímeros como nuestras representaciones inmediatas de ellos) es ineludible para un hablante, porque hablar acerca del mundo lleva consigo diferenciar la caracterización de la identificación de objetos (los usos referenciales del lenguaje, de los usos predicativos; los tipos comunes a distintos individuos, de las muestras de un mismo individuo) y contar lo que pasa en ese mundo no es sino caracterizar objetos identificados con relaciones de continuidad y conexión que perduran más allá de nuestros tropiezos con ellas, y que no son por principio inaprehensibles para otros hablantes. 
con ello, de verdad, debe guardar una conexión sistemática con los viejos esquemas básicos relegados, conexión que se ha de manifestar en la capacidad de los nuevos esquemas para interpretar o traducir los viejos.

Si ceñimos el idealismo trascendental a estos sobrios términos, hemos también de entender de forma templada la disyunción kantiana entre fenómenos y noúmenos —o entre las cosas como se nos aparecen en gracia a nuestro aparato sensible y conceptual, y las cosas en sí. La noción de noúmeno asume diversas funciones en el sistema global kantiano, pero incluso acotada en su moderada función de "idea límite negativa" arrastra consigo una importante matización del idealismo trascendental que hemos definido. ${ }^{36}$ El cambio histórico de esquemas conceptuales mantiene una continuidad básica en la medida en que los esquemas últimos dispongan de recursos para la interpretación de los esquemas pasados. Pero con los recursos mismos de nuestro esquema conceptual básico presente, afirma Kant, nos es dado pensar, si bien no conocer, esquemas conceptuales inconmensurables con los nuestros que se apliquen al mismo mundo. En cuanto que las apariencias del mundo habrían de ser en cada caso distintas y, sin embargo, en cada caso las apariencias serían apariencias del mismo mun-

36 Sobre esa función moderada, véase Nicholas Rescher, Kant's Theory of Knowledge and Reality, Washington, Univ. Press of America, 1983, pp. 1-16. En este punto recapitulamos a Kant orientando de nuevo el énfasis de la cuestión sobre la especificidad de los esquemas conceptuales humanos, en detrimento de la especificidad de sus aparatos sensibles. De esta manera eludimos la consideración de la equívoca tendencia de Kant a establecer una asimilación entre las cualidades primarias y las cualidades secundarias. Si aceptáramos esta inconveniente asimilación, que entra en conflicto con el talante de la primera Analogía y de la Refutación del Idealismo, tendríamos que admitir también, en contra de lo que parece razonable, que tan vacuo como es explicar el hecho de que ciertas cosas las percibimos como verdes a causa de su verdez, sería también explicar que percibimos un objeto como cuadrado a causa de la naturaleza espacial del objeto. 
do, Kant consideró útil llamar "cosas en sí" o "noúmenos" a la realidad que distintos esquemas conceptuales inconmensurables organizan. Esto quiere decir que Kant atribuyó completa sindéresis a la representación de que puedan surgir en el mundo, o llegar a él, seres racionales cuyos sistemas cognoscitivos sean necesariamente de todo punto incomprensibles para nosotros (donde "nosotros" designa la clase natural entera del género humano, y no un grupo o comunidad particulares).

Como ésta es una puntualización que añade algo nuevo al sucinto idealismo trascendental que hemos tipificado, hemos de distinguir esa versión sucinta, llamémosla IT, de la versión de idealismo trascendental matizada, llamémosla ITM, sugerida por la doctrina kantiana del noúmeno. ${ }^{37} \mathrm{La}$ matización en cuestión introduce otra dirección realista, que no hemos aún considerado. El punto clave de IT es perfectamente congeniable con el realismo empírico, toda vez que subraya la dependencia de los hechos respecto al lenguaje proposicional y, con ello, la función de predicado de proposiciones del predicado verdad, al tiempo que deja intocada la independencia de los hechos, o de las proposiciones empíricas, respecto al juicio particular de los sujetos. ITM no devuelve a los hechos también la independencia respecto del lenguaje; es decir, no afirma que no sea paradójico pensar que nuestra representación general de lo que es un hecho empírico o un estado de cosas antecede a condiciones de sentido ya constituidas. Sin embargo, el matiz de ITM acota las capacidades humanas de comprensión de tal manera que concede independencia al mundo como un todo respecto a todo lenguaje humano actual y posible.

Según ITM no estaríamos, entonces, únicamente limitados en lo que contingentemente podemos conocer, sino

37 Thomas Nagel ha argumentado recientemente en favor de un género de ontología realista cuyo tono armoniza muy bien con la característica matización de ITM. Vid. Thomas Nagel, op. cit., pp. 90-110. 
también en lo que nos es dado concebir. Es decir, ITM no dice simplemente que en el mundo se dan hechos que no conocemos, pero que sí cabe en principio que conozcamos porque se ajustan, en tanto hechos, a las capacidades conceptuales que nos habilita nuestro lenguaje, sino que dice además que el mismo mundo como un todo es, en alguna inefable dimensión, inconcebible en absoluto para nosotros en virtud de nuestra limitada naturaleza racional. No se trata, pues, ni de que hay realidades que aún no conocemos, ni de que hay realidades de las que hoy no podemos hacernos ninguna idea, pero acerca de las cuales un desarrollo conceptual o científico posible nos facilitaría la formación de creencias verdaderas o falsas. Tampoco se trata de que algo que ahora nos resulte positivamente inconcebible - que esta piedra esté pensando en Viena, que haya un cuadrado redondo, etc. - sea posible. Se trata de que cabe que haya dimensiones reales de las que no podremos nunca llegar a tener concepción alguna, ni verdadera, ni falsa, y que no están en ninguna relación concebible, próxima o lejana, con nuestras concepciones posibles. Tendría fundamento pensar que esas sombras, para nosotros impenetrables, son, con todo, sombras de nuestro mundo en cuanto que "ser el valor de una variable en nuestras cuantificaciones universal o existencial no es necesariamente ser la referencia de un nombre o descripción específicos en nuestro lenguaje, puesto que tenemos ya el concepto general de todo, que incluye a la vez las cosas que podemos nombrar o describir y aquéllas que no podemos". 38

Recibido: 1o. de abril de 1993.

38 Thomas Nagel, op. cit., p. 98. 


\section{SUMMARY}

Trying to do justice to both poles of the sensual/conceptual dichotomy, Kant declared himself both Transcendental idealistic and Empirical realistic. The author of this paper - "Transcendental Idealism and Empirical Realism"- examines these two notions in the light of Leslie Stevenson's criteria of demarcation according to the degree of independence of the judgement in relation to the object of knowledge. Next, García Serrano submits to critical exam and contrasts two theories of reference: Keith Donnellan's "descriptivist theory", on the one hand, and Saul Kripke's "denotative theory" of the reference of proper names, on the other. Finally, the author reformulates the Kantian argument of the transcendental deduction in "more familiar terms", attending to the contemporary theories examined.

[Laura Lecuona] 